\title{
Cobrança pelo uso da água para o saneamento: mecanismos para incentivo a eficiência e atendimento ao uso mínimo
}

\author{
Freshwater use charging for sanitation: mechanisms \\ to encourage efficiency and meet the basic needs
}

Telma Cristina Silva Teixeira** (D), José Paulo Soares Azevedo² (D), Denis Luc Louis Julien ${ }^{3}$ (i)

口-

\begin{abstract}
RESUMO
A cobrança pelo uso da água como instrumento econômico de gestão deve orientar os usuários quanto ao valor do recurso hídrico e incentivar o combate ao uso perdulário. Metodologias recentes inserem mecanismos relacionados às boas práticas no uso da água, mensurado no saneamento por meio do indicador de perdas percentuais na distribuição. Contudo, desprezam-se as perdas ocorridas nas etapas anteriores, bem como a essencialidade do serviço para a sociedade. Usando variáveis que abarcam todo o sistema de abastecimento desde a captação, este trabalho propôs uma metodologia de cobrança que amplia e penaliza as perdas reais, ao mesmo tempo em que permite descontos decorrentes da retirada para atendimento às necessidades mais fundamentais da população. Revela-se como resultado uma equação simples e transparente, com homogeneidade nas parcelas precificadas, que pode ter a punição e os privilégios ajustados às especificidades da bacia em que seja aplicada.
\end{abstract} Palavras-chave: abastecimento; cobrança; uso racional; uso mínimo; perdas.

\begin{abstract}
Freshwater use charging as an economic instrument must guide users as to the value of water resources and encourage the struggle against wasteful use. Recent methodologies include mechanisms related to good practices in the use of water resources, measured in sanitation sector by the indicator of percentage losses in distribution. However, leakages that occurred in the previous stages are ignored, as well as the essentiality of the service for society. Using variables that cover the entire supply system since withdrawn point, this paper proposes a freshwater charging methodology that conceptually expand and penalizes real losses, while imputing discounts resulting from the water use to supply a minimum volume to meet basic needs of the population. The result is a simple and transparent equation, with homogeneity in the variables charged, which might have the punishment and privileges adjusted to the specificities of the watershed in which it is applied.
\end{abstract}

Keywords: water supply; freshwater charge; rational use; basic needs use water losses

\section{INTRODUÇÃO}

Desde o pioneirismo da Bacia do Rio Paraíba do Sul (PBS) em 2003, a cobrança pelo uso da água vem sendo gradualmente implementada em bacias hidrográficas brasileiras. Em um contexto geral, as metodologias utilizadas baseiam-se em um somatório de três parcelas que se relacionam com as formas de uso do recurso hídrico (captação, consumo ou diluição de efluentes). Em casos específicos, como na Bacia do Rio São Francisco (BHSF), ocorre também o uso por derivação, referente à transposição das águas para fora dos limites da bacia.

Propostas de cobrança recentes (CNRH, 2014; 2016; 2018) vêm introduzindo na parcela de captação mecanismos associados às boas práticas no uso dos recursos hídricos, de forma a consolidar a cobrança como instrumento de gestão, contribuindo para ajustar a disponibilidade de água às efetivas necessidades de uso. No saneamento, utilizam-se como parâmetro as perdas na distribuição sem observar as etapas que ocorrem entre a captação e a efetiva distribuição ao consumidor final.

Dessa forma, os prestadores são penalizados pelos seus elevados índices de perdas que comprometem a disponibilidade de recursos hídricos para outros usos. Todavia, despreza-se a importância socioeconômica da atividade, visto que o setor de saneamento é responsável pelo atendimento ao direito constitucional ao serviço de abastecimento de água para a população.

$\square$

Universidade Estadual de Feira de Santana - Feira de Santana (BA), Brasil.

ZUniversidade Federal do Rio de Janeiro - Rio de Janeiro (RJ), Brasil.

${ }^{3}$ Grupo de Estudos em Recursos Hídricos e Sustentabilidade, Universidade Estadual de Feira de Santana - Feira de Santana (BA), Brasil.

*Autora correspondente: telma@uefs.br

Conflitos de interesse: os autores declaram não haver conflito de interesses.

Financiamento: nenhum.

Recebido: 06/01/2020 - Aceito: 30/05/2020 - Reg. ABES: 20200003 
Necessário, portanto, compatibilizar a essencialidade do serviço de abastecimento com seu histórico de uso perdulário, explicitando o valor atribuído a ambos os fatores: essencialidade e racionalidade. Assim, sendo a cobrança o instrumento econômico de gestão, responsável por estimular a racionalidade e dar conhecimento do valor da água, é lícito considerar que a partir dela seja implementada a punição ao desperdício e os benefícios associados à importância do setor. Ademais, considerando a captação como a parcela básica em que podem ser observados esses elementos, ela é indicada como objeto de transformação sem prejuízo à manutenção da cobrança das demais parcelas, relativas ao consumo e à diluição de efluentes.

Relevante ainda considerar que a cobrança pelo uso da água bruta deve se apresentar em uma estrutura simples, transparente e prognóstica, permitindo aos usuários e à sociedade a clara compreensão dos elementos precificados, bem como projeções que orientem seus planejamentos (TEIXEIRA, 2012; TEIXEIRA; AZEVEDO, 2013).

Assim, o presente trabalho teve por objetivo propor uma alternativa metodológica de cobrança pela captação da água bruta para o setor de saneamento incorporando critérios de racionalidade (controle de perdas) e atendimento a usos básicos (oferta mínima).

\section{METODOLOGIA}

Os conceitos básicos sobre os quais se estabelece a proposta são: as perdas de água e o volume mínimo necessário para atendimento às necessidades básicas. Esses conceitos são aprofundados na sequência, antecedendo uma breve discussão acerca da base de dados, variáveis e parâmetros utilizados para construção da proposta metodológica de cobrança pretendida.

\section{As perdas de água}

Lambert e Hirner (2000) apresentam o conceito padronizado de perdas de água como a diferença entre o volume que ingressa no sistema e o consumo autorizado, podendo o cômputo ser feito também em etapas separadas de transmissão e distribuição. Tais perdas podem ser classificadas como aparentes, decorrentes de consumo não autorizado ou mensuração errônea, ou reais, também chamadas de físicas, decorrentes de vazamentos e extravasamentos em diversos pontos ao longo do sistema. As primeiras impactam na receita das empresas prestadoras dos serviços e nos seus indicadores de performance financeira. As segundas, além dos prejuízos financeiros, implicam diretamente nas boas práticas no uso dos recursos hídricos, posto que revelam desperdício de volumes captados e redução da disponibilidade para concessão de outorga a outros usuários e usos.

Considerando as orientações e padronizações da International Water Association (IWA), mas ciente da ausência de uma terminologia comum, desde 1995, o Sistema Nacional de Informações sobre Saneamento (SNIS) sistematiza dados, informações e indicadores de abastecimento de água e esgotamento sanitário na publicação Diagnóstico dos Serviços de Água e Esgoto (DA\&E) (BRASIL, 2019). A partir dos dados autodeclarados pelos prestadores, o DA\&E apresenta os indicadores de perdas nos sistemas de abastecimento em três medidas distintas: em percentual (IN049: Índice de perdas na Distribuição), em litros diários por ligação (IN051: Índice de Perdas por Ligação) e em metros cúbicos diários por quilômetro de rede (IN052: Índice Bruto de Perdas Lineares). Os três indicadores baseiam-se no Volume de Água Produzido (AG006) medido ou estimado na saída da Estação de Tratamento de Água (ETA) ou de Unidades de Tratamento Simplificado (UTS), não observando as etapas entre a captação e o tratamento.

Embora o SNIS declare que o levantamento de informações compromete a compreensão do que vem a ser perdas reais ou aparentes nos sistemas brasileiros, destaca-se o indicador IN049, utilizado em estudos como medida de avaliação e comparação de eficiência de sistemas. Apesar de críticas que indiquem a inadequação desse indicador para a avaliação de performance técnica ou comparativa entre sistemas (TARDELLI FILHO, 2015), o IN049 é sugerido também para mensurar as boas práticas na gestão de recursos hídricos nas bacias interestaduais dos rios Paraíba do Sul, São Francisco e Paranaíba (TEIXEIRA et al., 2019).

\section{Atendimento a necessidades básicas}

Em quantidade mínima para satisfação das necessidades básicas e em qualidade adequada aos diversos usos, a disponibilidade de água garante benefícios múltiplos aos seres humanos (FREITAS; MAGNABOSCO, 2018). Tratando-se de emprego e geração de renda, além da ocupação decorrente de postos de trabalhos mantidos para a criação e a manutenção da infraestrutura, o acesso à água potável melhora o aproveitamento escolar e reduz a incidência de doenças, bem como o número de afastamentos causados por essas (FUNASA, 2010), impactando positivamente sobre a produtividade do trabalhador e gastos públicos em saúde. Tais efeitos secundários do abastecimento configuram-se em externalidades positivas, que se estendem ao âmbito da saúde e promovem maior bem-estar da população.

Todavia, apesar da importância do saneamento, a universalização do abastecimento de água no Brasil enfrenta desafios: a ocupação desordenada do solo resulta em difícil acesso, complicando estruturalmente o serviço; as discussões quanto ao modelo institucional geram conflitos políticos e sociais (CASTRO, 2019); o lapso temporal entre a aplicação dos investimentos e os benefícios resultantes desestimula interesses eleitoreiros dos decisores; e o elevado volume de recursos pressiona e assusta as contas dos responsáveis.

Não sendo suficiente, a esses desafios pesa, ainda, sobre o setor o elevado índice de perdas reais que depõem contra os prestadores dos serviços. Revela-se então uma possível contradição: garantir a prioridade na retirada de água para o usuário que executa um serviço essencial à sociedade, mas que perde, na média nacional, mais de 30\% desse escasso recurso (BRASIL, 2019).

Diante do exposto, é razoável sustentar argumentos em defesa da ampliação de investimentos no setor, ao mesmo tempo em que se exige dele maior nível de racionalidade. Em mais, justo ainda considerar um tratamento diferenciado na aplicação da cobrança pelo uso da água em reconhecimento da importância social dos prestadores (TEIXEIRA, 2012). Entretanto, evitando o reforço à contradição exposta e reconhecendo os termos estabelecidos para a prioridade de uso - i.e., em situações de escassez —, é lícito restringir tais privilégios ao volume mínimo necessário para satisfação de necessidades básicas do ser humano.

Tal argumentação traz em si o questionamento do quanto vem a ser esse volume mínimo e a que uso estaria destinado. Gleick (1996), alertando para as possíveis adequações regionais decorrentes de diferenças climáticas ou culturais, entre outras, sugere $50 \mathrm{~L}$ diário por pessoa como suficiente para satisfazer necessidades de higiene pessoal, uso sanitário, cocção de alimentos e consumo direto. Por sua vez, Reed e Reed (2013) indicam o volume de 70 L como o suficiente, acrescendo aos usos citados a higiene de roupas e do ambiente doméstico, além do cultivo de alimentos em escala de consumo familiar.

Depreende-se então que o volume adequado às necessidades básicas deve garantir o uso mínimo para sobrevivência (ingestão e cocção de alimentos) e 
higiene pessoal, de roupas e ambiente. Assim, sendo os prestadores de serviços de saneamento os usuários de água bruta que suprem essas necessidades fundamentais, é lícito atribuir a eles mecanismos diferenciados de cobrança que formalizem a sua importância.

\section{Material e métodos}

A cobrança pela captação do recurso hídrico em um corpo dágua deve observar aspectos quantitativos, qualitativos e econômicos, tendo a bacia hidrográfica como centro de análise. Tratando-se da disponibilidade de recurso, a cobrança permite dar conhecimento ao usuário da sua escassez ou limitação no corpo hídrico onde ocorre a retirada. Nesse sentido, ao encaminhar uma demanda de outorga de direito de uso, o usuário deve ser incentivado a adequar sua solicitação a sua efetiva necessidade, evitando, assim, sub ou superdimensionamento. Assim, o volume outorgado $\left(Q_{o}\right)$ e, quando disponível, o volume efetivamente medido pelo usuário $\left(Q_{m}\right)$ formam a base quantitativa a ser valorada, sobre a qual incide os demais parâmetros.

Os aspectos qualitativos, por sua vez, são estabelecidos a partir de parâmetros específicos ao corpo hídrico onde ocorre a retirada. As classes de enquadramento das águas são exemplos de indicadores desses aspectos, evidenciando a adequabilidade do recurso em relação à atividade do usuário. O parâmetro que corresponde a esses aspectos é indicado por $\mathrm{K}_{\text {classe }}$.

Quanto aos aspectos econômicos, o primeiro parâmetro a ser decidido pelo Comitê é o preço unitário relacionado ao tipo de uso (captação) (PPU em $\mathrm{R} \$ / \mathrm{m}^{3}$ ), podendo esse ser também modificado considerando a racionalidade do usuário no uso da água, a disponibilidade hídrica da bacia, a relevância socioeconômica da atividade demandante, entre outros fatores.

Assim, a cobrança pela captação de recurso hídrico apresenta-se como uma função de múltiplas variáveis e parâmetros que se relacionam conforme decidido pelo Comitê de Bacia. Tem-se então uma estrutura simplificada que se baseia em um volume a ser valorado sobre o qual incidem os parâmetros de qualidade $\left(\mathrm{K}_{\text {classe }}\right)$ e precificação (PPU).

A partir dessa estrutura básica, observando a disponibilidade de dados que viabilizem a proposta, foram selecionadas variáveis e indicadores divulgados anualmente pelo DA\&E do SNIS. Para a valoração das perdas que comprometem o uso racional, foram observadas as variáveis que indicam as entradas e as saídas do recurso hídrico ao longo do sistema (Quadro 1), identificadas na estrutura do balanço hídrico com origem no ponto de captação (Figura 1).

Quadro 1 - Variáveis da cobrança associadas ao uso racional de recursos hídricos.

\begin{tabular}{|l|c|}
\hline Código & Descrição \\
\hline AG006 & Volume anual de água produzido pelo prestador, em $\mathrm{m}^{3}$. \\
\hline AG007 & $\begin{array}{r}\text { Volume anual de água submetido a tratamento, medido na saída das } \\
\text { ETAs, em } \mathrm{m}^{3} \text {. Contêm o volume bruto importado (AGO16). }\end{array}$ \\
\hline AG010 & Volume anual de água consumido pelos usuários, em $\mathrm{m}^{3}$. \\
\hline AG016 & $\begin{array}{c}\text { Volume anual de água bruta importado, em } \mathrm{m}^{3} \text {. É parte do produzido } \\
\text { (AG006). }\end{array}$ \\
\hline AG017 & Volume anual de água bruta exportado, em $\mathrm{m}^{3}$. \\
\hline AG018 & Volume anual de água tratada importado, em $\mathrm{m}^{3}$. \\
\hline AG019 & Volume anual de água tratada exportado, em $\mathrm{m}^{3}$. \\
\hline AG024 & Volume anual de água de serviço, em $\mathrm{m}^{3}$. \\
\hline
\end{tabular}

ETA: Estação de Tratamento de Água.

Fonte: Brasil (2019).
Adverte-se que, na Figura 1, algumas variáveis foram omitidas:

- O volume de água de serviço (AG024) é computado em diversas etapas do sistema, não sendo possível sua precisa indicação na estrutura representada;

- A variável AG010 inclui estimativas de consumo não hidrometradas, além do volume de água exportado após o tratamento (AG019). Logo, a representação dessa variável na estrutura do balanço pode gerar compreensão equivocada quanto a sua exatidão.

Para a precificação do uso mínimo, observa-se que as estimativas populacionais do DA\&E se baseiam em estatísticas de dados demográficos oficiais Assim, manteve-se a base para coleta de variáveis relacionadas ao atendimento do uso mínimo de água (Quadro 2).

Mantendo os parâmetros iniciais de classe de enquadramento e precificação, a proposta consiste na modificação do volume de recurso hídrico a ser valorado na captação de forma a incorporar a ele perdas de recurso, tomando a retirada como ponto de partida, ao mesmo tempo em que se valora o reconhecimento do abastecimento como uso definido como mínimo.

\section{RESULTADOS}

O valor anual cobrado do prestador de serviços de abastecimento $\left(\mathrm{C}_{\text {san }}\right)$, incluindo perdas de água bruta e tratada e atendimento às necessidades mínimas de uso, passa a ser expresso conforme a Equação 1:

$C_{\text {san }}=\left(Q_{m}+Q_{e f}\right) \times P P U \times K_{\text {classe }}$

Em que:

$\mathrm{C}_{\mathrm{san}}=$ valor anual da cobrança pela captação no setor de saneamento, em R\$;

$\mathrm{Q}_{\mathrm{m}}=$ volume anual medido, em $\mathrm{m}^{3}$;

$\mathrm{Q}_{\mathrm{ef}}=$ volume anual de eficiência, em $\mathrm{m}^{3}$;

A variável $Q_{m}$ permite a cobrança em sua forma mais simplificada, precificando por quantidade consumida com base nos princípios fundamentais da teoria econômica. Adiciona-se a ela a variável calculada $\mathrm{Q}_{\mathrm{ep}}$ que sistematiza o somatório de variáveis básicas da cobrança, multiplicadas por parâmetros específicos que ponderam a racionalidade de uso do prestador. Penaliza-se a ineficiência, além dos limites econômicos e técnicos admissíveis à bacia, reconhecendo a essencialidade do serviço e garantindo um volume mínimo em precificação diferenciada. Dessa forma, a variável $\mathrm{Q}_{\mathrm{ef}}$ torna-se resultado da soma de quatro termos individualmente definidos, conforme a Equação 2.

$Q_{e f}=Q_{O} \times K_{O}+Q_{p d} \times K_{p d}+Q_{p b} \times K_{p b}-Q_{u} \times K_{u}$

Em que:

$\mathrm{Q}_{\mathrm{o}}$ : volume anual outorgado, em $\mathrm{m}^{3}$;

$\mathrm{K}_{\mathrm{o}}$ : parâmetro adimensional de ponderação do volume outorgado;

$\mathrm{Q}_{\mathrm{pd}}$ : volume anual de perdas na distribuição, em $\mathrm{m}^{3}$;

$\mathrm{K}_{\mathrm{pd}}$ : parâmetro adimensional de ponderação do volume de perdas na distribuição; $\mathrm{Q}_{\mathrm{pb}}$ : volume anual de perdas pré-tratamento, em $\mathrm{m}^{3}$;

$\mathrm{K}_{\mathrm{pb}}$ : parâmetro adimensional de ponderação do volume de perdas pré-tratamento; $\mathrm{Q}_{\mathrm{u}}$ : volume anual de uso mínimo, em $\mathrm{m}^{3}$;

$\mathrm{K}_{\mathrm{u}}$ : parâmetro adimensional de ponderação do volume de uso mínimo. 


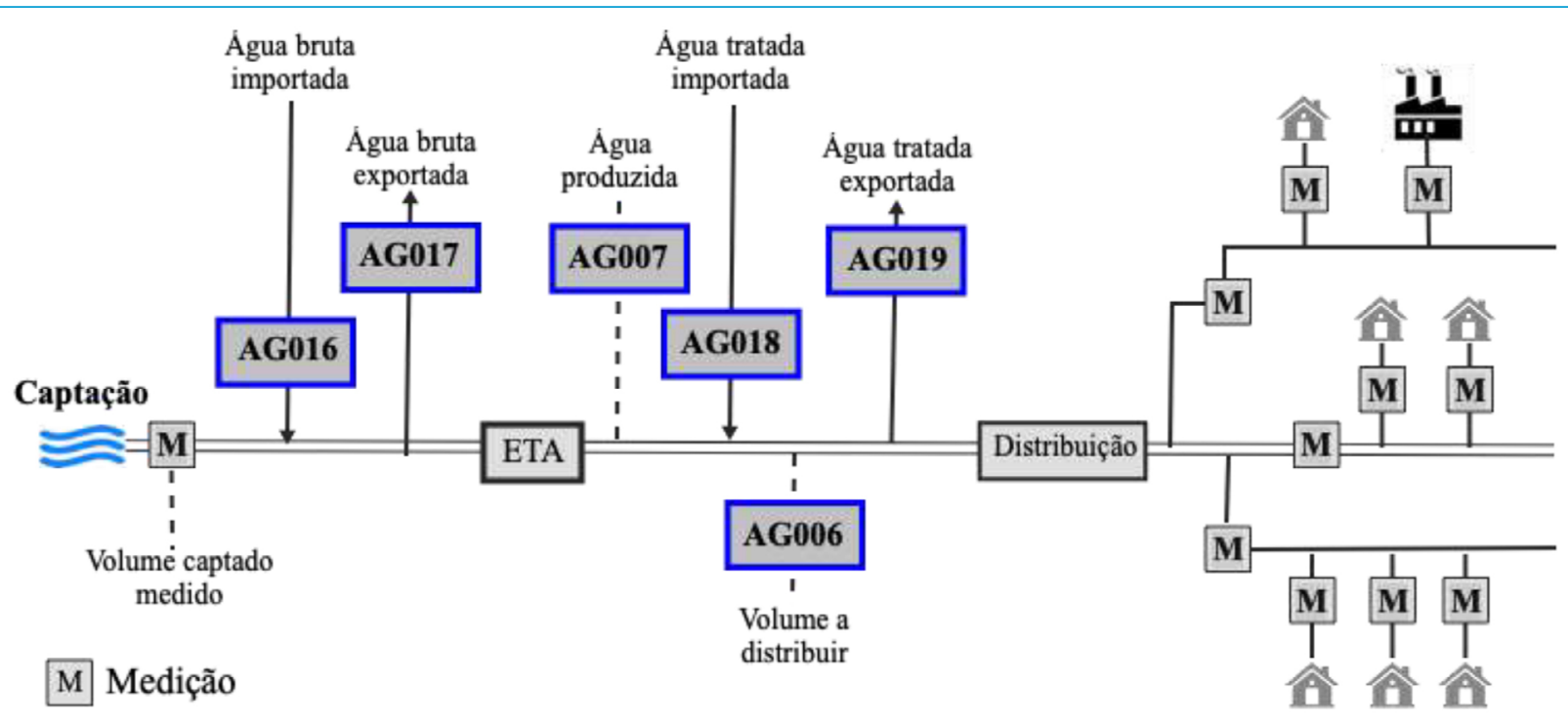

ETA: Estação de Tratamento de Água.

Fonte: adaptado de Lambert e Hirner (2000) e Brasil (2019).

Figura 1 - Identificação das variáveis Sistema Nacional de Informações sobre Saneamento no balanço hídrico.

Quadro 2 - Variável e parâmetro da cobrança associados ao uso mínimo.

\begin{tabular}{|l|c|c|}
\hline Tipo & Código & Descrição \\
\hline Variável & $P_{\mathrm{opA}}$ & $\begin{array}{r}\text { População atendida com abastecimento de água, em } \\
\text { habitantes (AGOO1). }\end{array}$ \\
\hline Parâmetro & $\mathrm{V}_{\text {min. }}$ & $\begin{array}{r}\text { Volume diário per capita de água para uso mínimo, em } \\
\text { litros (definido pelo Comitê). }\end{array}$ \\
\hline
\end{tabular}

Fonte: para a variável, Brasil (2019).

Cada um desses termos é calculado com base nas variáveis indicadas pelos Quadros 1 e 2, a partir de critérios que consideram sempre a gestão dos recursos hídricos da bacia como objeto central de análise.

\section{Outorga}

$\mathrm{O}$ primeiro termo, referente à outorga $\left(\mathrm{Q}_{\mathrm{o}} \times \mathrm{K}_{\mathrm{o}}\right)$, precifica o volume autorizado pelo órgão gestor reconhecendo que a concessão do direito de uso limita a disponibilidade hídrica para outros usuários. Por conseguinte, enquanto se faz necessário valorar a demanda de outorga per si, observa-se a possível superestimação do volume solicitado pelo prestador, criando mecanismos financeiros punitivos para a reserva de disponibilidade ou a captação em volume superior ao autorizado.

O parâmetro adimensional $\left(\mathrm{K}_{\mathrm{o}}\right)$ que pondera o volume outorgado é estabelecido com base na razão entre $Q_{o} e Q_{m}$, tendo limite mínimo não nulo, que permite computar o valor condominial da cobrança, em que todos os usuários contribuem pelo uso do bem comum, que é o corpo hídrico. Em seu valor máximo, esse parâmetro penaliza a reserva de outorga que ocorre quando o volume solicitado é muito além do efetivamente medido e o uso não é autorizado, ou seja, quando o $Q_{m}$ é superior ao $Q_{0}$. Relevante considerar que, para fins de melhoria da gestão, incentiva-se o usuário a implementar instrumentos de medição. Logo, em situações em que esses não se encontram presentes, sugere-se utilizar o máximo $\mathrm{K}_{\mathrm{o}}$. Ademais, no âmbito administrativo, é indicado ainda que seja solicitada revisão de outorga em situações de reserva ou mesmo de captação excedente.

\section{Perdas na distribuição}

As perdas na distribuição $\left(\mathrm{Q}_{\mathrm{pd}} \times \mathrm{K}_{\mathrm{pd}}\right)$ evidenciam a complexidade na gestão de recursos hídricos considerando a compatibilização entre os múltiplos usos e a limitada disponibilidade hídrica. Como indicador dessa medida, utiliza-se de forma mais comum a razão entre os volumes fisicamente perdido e produzido/ disponibilizado, indicada pelo IN049 (Equação 3), utilizado em metodologias de cobrança em bacias brasileiras.

$I N 049=\frac{A G 006+A G 018-A G 010-A G 024}{A G 006+A G 018-A G 024} \times 100$

Contudo, esse indicador, sendo um percentual, não permite evidenciar o volume de recurso efetivamente perdido e sua significância diante da disponibilidade hídrica da bacia. Ademais, nos dados autodeclarados pelos prestadores no diagnóstico do SNIS, o volume a distribuir (AG006) incorpora também recursos provenientes de outras fontes (importada de outro sistema ou água subterrânea), tornando possível o enviesamento de dados específicos para a bacia em que ocorre a cobrança.

Dessa forma, estima-se o volume de água perdida após tratamento em ETAs $\left(\mathrm{Q}_{\mathrm{pd}}\right)$ como o produto da perda de água na distribuição pela proporção de água produzida, conforme indicado na Equação 4. De forma mais explícita, o primeiro termo considera o índice de perda na distribuição ( $\mathrm{I}_{\mathrm{pd}}$, Equação 5), que é aplicada sobre o volume produzido que tem origem no corpo hídrico, eliminando assim distorções provenientes de volumes de água subterrânea que possam entrar no sistema. Obtêm-se então o volume perdido, em $\mathrm{m}^{3}$, a ser devidamente valorado de acordo com a sua representatividade quantitativa, o que não ocorre quando se utiliza um indicativo percentual, como acontece com o IN049. 
$Q_{p d}=I_{p d} \times A G 007$

$I_{p d}=\frac{(A G 006+A G 018)-(A G 010+A G 024)}{(A G 006+A G 018)}$

A penalização pelas perdas na distribuição é computada pelo parâmetro adimensional $\mathrm{K}_{\mathrm{pd}}$, que é função do $\mathrm{I}_{\mathrm{pd}}$. $\mathrm{O} \mathrm{K}_{\mathrm{pd}}$ penaliza, assim, o volume efetivamente perdido, eliminando as distorções decorrentes de usos percentuais que não permitem considerar a significância do uso perdulário para a bacia. Ratifica-se que a formulação aqui apresentada resulta em informações de grande importância para o gestor dos recursos hídricos.

\section{Perdas pré-tratamento}

Ainda em alusão ao uso racional, a parcela de perda bruta $\left(\mathrm{Q}_{\mathrm{pb}} \times \mathrm{K}_{\mathrm{pb}}\right)$ amplia o conceito usualmente adotado, posto que, na gestão da bacia, faz-se importante observar não apenas a eficiência do prestador no processo de distribuição, e sim em todo o sistema, tomando como ponto de partida o ponto de captação, mas deixando de lado recursos hídricos que não são oriundos da bacia, como a água importada, bruta ou tratada, ou a água subterrânea. Assim, estima-se o volume de água retirada perdida antes da distribuição $\left(\mathrm{Q}_{\mathrm{pb}}\right)$ como o produto do índice de perdas brutas ( $\mathrm{I}_{\mathrm{pb}}$ Equação 6) pelo $\mathrm{Q}_{\mathrm{m}}$ pelo prestador de serviço, ou $\mathrm{Q}_{\mathrm{o}}$, caso não exista medição (Equação 7).

$I_{p b}=\frac{\left(Q_{m}+A G 016\right)-(A G 017+A G 007)}{\left(Q_{m}+A G 016\right)}$

$Q_{p b}=I_{p b} \times Q_{m}$

De forma análoga ao que acontece com as perdas na distribuição, penaliza-se essa parcela, que caracteriza uso perdulário com base em um parâmetro adimensional $\mathrm{K}_{\mathrm{pb}}$, que é função do próprio $\mathrm{I}_{\mathrm{pb}}$. Observando que as variáveis selecionadas permitem estimar os volumes vazados antes da ETA, é lícito caracterizar essa parcela da cobrança como uma efetiva ampliação da mensuração das perdas.

\section{Uso mínimo}

A parcela da cobrança que incorpora o uso mínimo $\left(\mathrm{Q}_{\mathrm{u}} \times \mathrm{K}_{\mathrm{u}}\right)$ evidencia a formalização da essencialidade da água, bem como os múltiplos benefícios advindos dela. Toma-se como referência um volume mínimo adequado para atendimento das necessidades diárias $\left(\mathrm{V}_{\text {minn }}\right)$, definido pelo Comitê de Bacia a partir de suas especificidades regionais, e a população efetivamente atendida pelo serviço (PopA), de forma a estimular investimentos para a universalização do abastecimento. Determina-se assim o volume de recurso necessário para a satisfação do uso mínimo da população $\left(\mathrm{Q}_{\mathrm{PopA}}\right.$, Equação 8).

$Q_{P o p A}=P o p A \times V_{m i ́ n}$.

A variável $Q_{u}$, que representa o volume mínimo para atendimento às necessidades básicas, tem valor estabelecido a partir da comparação entre $\mathrm{Q}_{\mathrm{PopA}}$ e o resultado da diferença entre o volume disponível para distribuição (AG006) e o volume de água tratada exportado (AG019), conforme a Equação 9.

$Q_{u}=\min \left\{Q_{P o p A} ;(A G 006-A G 019)\right\}$
Se $Q_{P o p A}$ não for atingido, o prestador é socialmente ineficiente, então $Q_{u}=$ (AG006 - AG019), ou seja, assume-se como volume mínimo a quantidade de água disponível para distribuição aos habitantes. Em caso contrário, buscando a racionalidade no uso, estabelece-se $\mathrm{Q}_{\mathrm{u}}=\mathrm{Q}_{\mathrm{PopA}}$, eliminando a parcela de consumo superior às necessidades mínimas diárias.

O peso atribuído ao desconto dessa parcela é definido pelo parâmetro adimensional $\mathrm{K}_{\mathrm{u}}$ que, por sua vez, é função crescente de um índice de uso mínimo $\left(\mathrm{I}_{\mathrm{u}}\right)$, conforme razão indicada pela Equação 10. Dessa forma, está implícito, nesse índice, a meta de universalização do serviço de abastecimento, que implicaria em $\mathrm{Q}_{\mathrm{u}}=\mathrm{Q}_{\mathrm{PopA}}$, permitindo o máximo possível de desconto, ao mesmo tempo em que se promove a racionalização do uso, eliminando descontos em volumes de água superiores às necessidades básicas. Ademais, elimina-se também a possibilidade de nova penalização das perdas, que poderia acontecer se a variável AG010 fosse considerada como comparativo, posto que, nela, as perdas já estão computadas.

$I_{u}=\frac{Q_{u}}{Q_{P o p A}}$

\section{Os parâmetros adimensionais $\mathrm{K}_{\mathrm{u}}, \mathrm{K}_{\mathrm{pd}}, \mathrm{K}_{\mathrm{pb}}$ e $\mathrm{K}_{\mathrm{u}}$}

Em todas as parcelas da cobrança pela captação para os prestadores de serviço de abastecimento de água, a intensidade dos parâmetros adimensionais indicados por K é de decisão do Comitê de Bacia, podendo se apresentar como função crescente dos respectivos índices $\mathrm{I}_{\mathrm{u}}, \mathrm{I}_{\mathrm{pd}}$ e $\mathrm{I}_{\mathrm{pb}}$, conforme exemplificado na Figura 2.

A parcela de uso mínimo é precedida por sinal negativo, caracterizando, assim, o desconto. Nas demais parcelas, mantêm-se o sinal positivo, que indica a penalização pelo uso perdulário. Da mesma forma, os valores mínimos e máximos são também arbitrariamente estabelecidos pelos comitês, considerando aspectos locais das bacias onde se aplica a cobrança.

Relevante considerar que, para as perdas de forma geral, é mister observar os limites técnicos e econômicos mínimos de redução das perdas em todo o sistema, conforme orientado por Farley et al. (2008). Os autores alertam que, embora desejável, é impossível eliminá-las por completo do sistema.

Sugere-se que o $\mathrm{K}_{\mathrm{o}}$ seja objeto de atenção distinta, posto que ele tem como objetivo valorar o direito de uso da água, em um sentido de participação condominial do usuário, evitando assim a possível duplicidade de cobrança sobre volumes que já foram computados nas demais parcelas. Portanto, ratifica-se o exposto anteriormente, estabelecendo para $\mathrm{K}_{\mathrm{o}} \mathrm{um}$ mínimo condominial e valores máximos que indiquem a reserva de água e a captação excedente, podendo haver diferenciação nesses últimos casos (Figura 3).

\section{DISCUSSÃO}

A valoração das perdas nos sistemas de abastecimento concretiza-se como um desafio ao processo de gestão na tentativa de eliminar o encadeamento entre mecanismos que induzem ao uso racional e o repasse de custos via tarifa ao consumidor final (ACSELRAD; AZEVEDO; FORMIGA-JOHNSSON, 2015). Não sendo possível ao Comitê de Bacia intervir nas decisões internas das empresas de saneamento, identificar de forma explícita a eficiência no uso do recurso disponibilizado torna-se, então, uma informação vital para a boa governança hídrica, possibilitando ações efetivas que efetivamente modifiquem o 


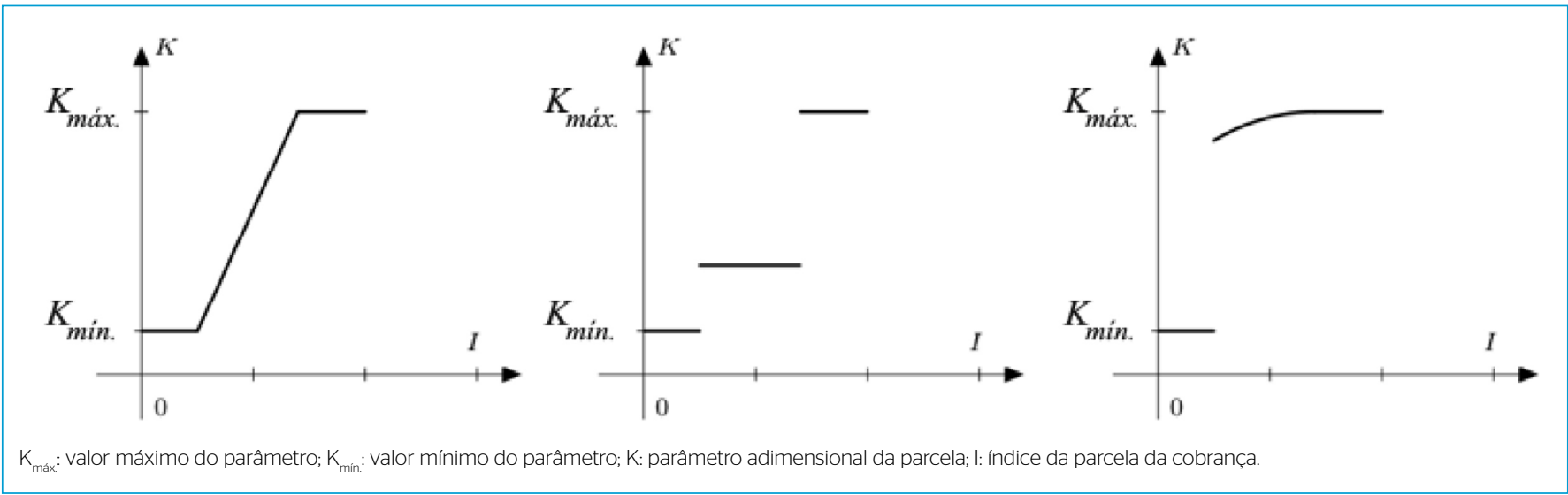

Figura 2 - Tipos de funções crescentes para definição dos parâmetros $\mathrm{K}_{\mathrm{u}^{\prime}}, \mathrm{K}_{\mathrm{pd}} \mathrm{eK}_{\mathrm{pb}}$.

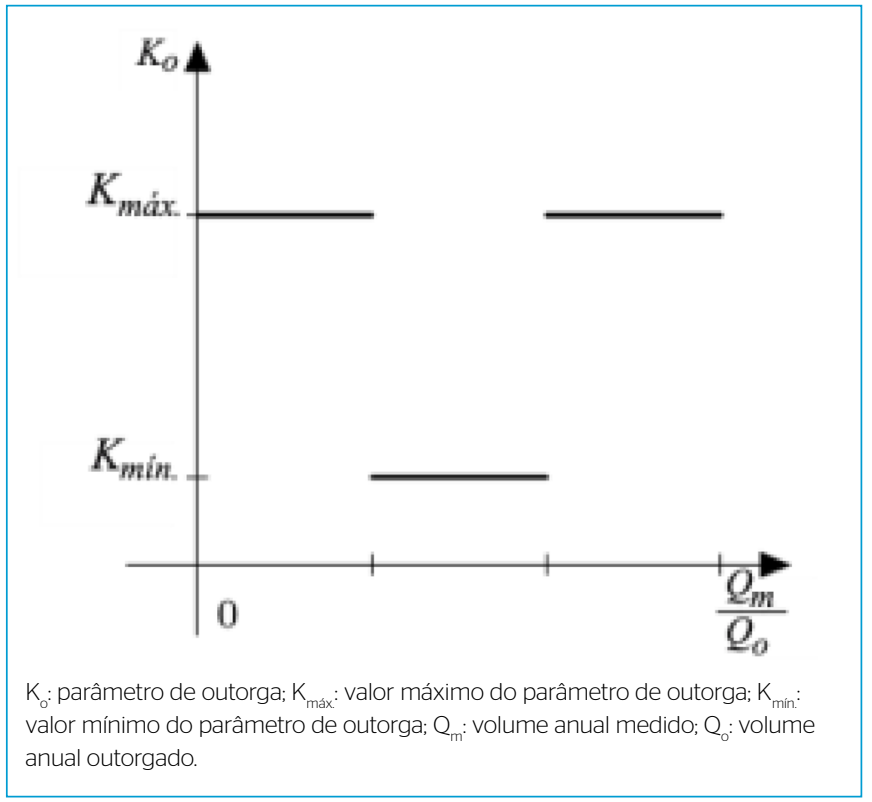

Figura 3 - Exemplo de função para definição do parâmetro $\mathrm{K}_{\circ}$.

desempenho do prestador de serviços de saneamento. Com isso, e tendo como objeto central a bacia hidrográfica, as parcelas de volumes a serem precificados da Equação 2 têm como princípio a gestão de recursos hídricos, o que pode ser constatado na forma de cálculo dos volumes.

No combate ao uso perdulário, amplia-se o espectro das perdas, quantificando-as em duas partes. Na primeira, insere-se mecanismos que permitem computar o volume de água perdido no transporte do recurso até a ETA. $\mathrm{Na}$ segunda, em $\mathrm{Q}_{\mathrm{pd}}$, verifica-se uma alternativa distinta do indicador IN049, até então utilizado como parâmetro para cobrança pelo uso perdulário. As variáveis calculadas $\mathrm{Q}_{\mathrm{pb}}$ e $\mathrm{Q}_{\mathrm{pd}}$, expressas em $\mathrm{m}^{3}$, tornam possível mensurar a importância relativa desse desperdício em face da disponibilidade hídrica da bacia e para os custos do usuário. Então, torna-se possível melhor tomada de decisão quanto aos investimentos dos prestadores per si, bem como dos recursos próprios da bacia quanto a ações relacionadas ao aumento da disponibilidade hídrica.
Assim, em situações de escassez extrema, faz-se possível não apenas garantir o uso prioritário aos prestadores que revelam eficiência operacional, mas também dar a correta indicação do volume mínimo necessário para o atendimento às necessidades básicas, evitando imposição de racionamentos ou mesmo suspensão de captação por outros usos para garantir a prioridade legalmente estabelecida.

Alternativamente, ainda em períodos de escassez, usuários perdulários são revelados expondo o desperdício com base nos diferenciais entre o volume produzido e o disponibilizado à distribuição, localizando na estrutura do balanço hídrico em que ocorrem os vazamentos e previamente indicando os investimentos. A forma como a proposta apresentada corrobora essa argumentação é evidenciada na justa identificação das parcelas a serem valoradas, em unidades de medida que permitem ainda auferir a significância também dessas perdas frente a disponibilidade hídrica da bacia. Assim, computando em separado as perdas, evita-se a complexidade na apresentação e até mesmo equívocos quanto à aplicação da punição, conforme revelado por Teixeira et al. (2019).

Tratando-se da valoração do volume mínimo, diversos elementos devem ser observados:

- $\mathrm{O}$ cômputo de $\mathrm{Q}_{\mathrm{u}}$ formaliza a relevância do setor como fornecedor de um serviço essencial à sociedade;

- Ao quantificar o volume mínimo, são fornecidas informações aos prestadores que podem ratificar suas decisões internas relacionadas à definição de faixas de consumo e respectivas tarifas a serem cobradas aos consumidores;

- A progressividade do desconto relaciona-se diretamente à população atendida, criando estímulo às iniciativas que levem à universalização dos serviços de abastecimento e, por conseguinte, aos múltiplos benefícios ao bem-estar da população;

- O conhecimento de $\mathrm{Q}_{\mathrm{u}}$ permite ao Comitê observar a ocorrência de insuficiência hídrica para o atendimento às necessidades mínimas de abastecimento, estimulando ações e investimentos nas bacias que aumentem a disponibilidade de água;

- De forma indireta, $o Q_{u}$ evidencia a existência ou não de boas práticas no uso do recurso hídrico pelo prestador e pelos consumidores finais.

Por seu turno, os parâmetros adimensionais que modificam os volumes calculados para precificação têm como base variáveis distintas que impedem 
a duplicidade na penalização ou a anulação do desconto. Destaca-se que a inclusão do desconto pelo volume mínimo ponderado com base no $I_{u}$ evidencia a escolha de variáveis que têm como objeto a produção de água para abastecimento, e não o indicado como disponível ao consumo, como ocorre no IN049.

É relevante ainda ratificar que todas as variáveis e os parâmetros que compõem a função permitem decisões que facilitam a arbitragem do Comitê quando da decisão dos parâmetros adimensionais, posto que esses resultam de funções pertinentes à própria bacia. Ademais, existe homogeneidade nas parcelas, apresentadas em $\mathrm{m}^{3}$, dando aos usuários e ao Comitê a clara noção do que está sendo precificado.

Em relação à fonte das variáveis utilizadas na proposta, é relevante reconhecer que o DA\&E do SNIS, ao longo das 24 edições já apresentadas, tem gradativamente ampliado o número de participantes que respondem às chamadas de coleta de dados. Embora o relatório tenha como objeto de análise os prestadores de serviços, a multiplicidade de variáveis desagregadas por município fornece informações fundamentais para a gestão de recursos hídricos. Assim, conjecturas acerca da confiabilidade dos dados voluntariamente declarados devem ser combatidas com melhoria nos mecanismos de verificação de inconsistências já existentes, sem o descarte das informações do DA\&E. Ademais, metodologicamente, o SNIS revela-se ciente das dificuldades relacionadas à padronização terminológica dos termos do balanço hídrico, detalhadamente descrevendo as variáveis apresentadas. Assim, é justo supor que é possível efetivamente traçar e computar o caminho da água no setor de abastecimento, desde o ponto de captação até sua chegada no hidrômetro das residências.

\section{CONCLUSÕES}

A cobrança pelo uso da água bruta no Brasil, mais de 15 anos após sua primeira implementação na Bacia do Rio PBS, ainda enfrenta o desafio de adequar princípios de boas práticas no uso dos recursos hídricos.

No setor de saneamento, responsável pelo necessário serviço de abastecimento, as relevantes perdas na distribuição, que caracterizam o desperdício da água, encontram como obstáculos adicionais ao seu enfrentamento os elevados volumes de investimentos e as metodologias de cobrança que desconsideram a essencialidade do uso da água feita por ele.

Diante dessas considerações, ciente da existência de limites técnicos e econômicos para o combate às perdas, a metodologia proposta combina estímulos à universalização do abastecimento de água, por meio do cômputo do uso mínimo na cobrança, com punições decorrentes das perdas de água, em todo o sistema, tendo como ponto de partida da análise o corpo hídrico em que ocorre a captação.

Assim, com parâmetros que observam as especificidades da bacia, especialmente quanto a sua disponibilidade hídrica, a proposta de cobrança pela captação de água para abastecimento incorpora critérios de boas práticas ao uso do recurso hídrico concomitantemente ao reconhecimento de prioridade do serviço oferecido pelo setor.

\section{CONTRIBUIÇÃO DOS AUTORES}

Teixeira, T.C.S.: Conceituação, Curadoria de Dados, Análise Formal, Metodologia, Escrita - Primeira Redação, Escrita - Revisão e Edição. Azevedo, J.P.S.: Supervisão, Visualização. Julien, D.L.L.: Análise Formal, Validação, Escrita - Revisão e Edição.

\section{REFERÊNCIAS}

ACSELRAD, M.V.; AZEVEDO, J.P.S.; FORMIGA-JOHNSSON, R.M. Cobrança pelo uso da água no Estado do Rio de Janeiro, Brasil (2004-2013): histórico e desafios atuais. Engenharia Sanitária e Ambiental, v. 20, n. 2, p. 199-208, 2015. https://doi.org/10.1590/S1413-41522015020000112026

BRASIL. Ministério do Desenvolvimento Regional. Secretaria Nacional de Saneamento. Sistema Nacional de Informações de Saneamento: 240 Diagnóstico dos Serviços de Água e Esgoto 2018. Brasília: SNS/MDR, 2019. $180 \mathrm{p}$

CASTRO, J.E. The Challenge of Universalizing Essential Water Services in Latin America and the Caribbean. In: PETRI, J.; MATTILA, H.R.; RAJALA, K.S.; STADDON, C. (org.). Resilient Water Services and Systems: The Foundation of Well-Being. Londres: IWA Publisher, 2019. p. 47-67.

CONSELHO NACIONAL DE RECURSOS HÍDRICOS (CNRH). Resolução no 162, de 15 de dezembro de 2014. Aprova os Mecanismos e Valores de Cobrança pelo Uso de Recursos Hídricos de Domínio da União na Bacia Hidrográfica do Rio Paraíba do Sul. Brasília: CNRH, 2014.

CONSELHO NACIONAL DE RECURSOS HÍDRICOS (CNRH). Resolução no 185, de 7 de dezembro de 2016. Aprova os Mecanismos e Valores de
Cobrança pelo Uso de Recursos Hídricos de Domínio da União na Bacia Hidrográfica do Rio Paranaíba. Brasília: CNRH, 2016.

CONSELHO NACIONAL DE RECURSOS HÍDRICOS (CNRH). Resolução no 199, de 28 de junho de 2018. Aprova os Mecanismos e Valores de Cobrança pelo Uso de Recursos Hídricos de Domínio da União na Bacia Hidrográfica do Rio São Francisco. Brasília: CNRH, 2018.

FARLEY, M.; WYETH, G.; GHAZALI, Z.; SINGH, S. The Manager's Non Revenue Water Handbook: A Guide to Understanding Water Losses. Londres: Ranhil Utilities Bernhad/USAID, 2008. 110 p.

FREITAS, F.G.; MAGNABOSCO, A.L. Benefícios Econômicos e Sociais da Expansão do Saneamento no Brasil. São Paulo: Ex Ante Consultoria Econômica e Instituto TrataBrasil, 2018. 86 p.

FUNDAÇÃO NACIONAL DE SAÚDE (FUNASA). Impactos na Saúde e no Sistema Único de Saúde Decorrentes de Agravos Relacionados a um Saneamento Ambiental Inadequado. Brasília: FUNASA, 2010. 246 p.

GLEICK, P.H. Basic Water Requirements for Human Activities: meeting basic needs. Water International, v. 21, n. 2, p. 83-92, 1996. https://doi. org/10.1080/02508069608686494 
LAMBERT, A.; HIRNER, W. Losses from Water Supply Systems: Standard Terminology and Recommended Performance Measures. The Blue Pages. London: IWA, 2000.

REED, B.; REED, B. How much water is needed in emergencies. In: REED, B. (org.). Technical Notes on Drinking Water, Sanitation and Hygiene in Emergencies. Leicestershire: Water, Engineering and Development Centre/ World Health Organization (WHO/WEDC), 2013. p. 35-38.

TARDELLI FILHO, J. Controle e Redução nos Sistemas Públicos de Abastecimento de Água - Posicionamento e Contribuições Técnicas da ABES. In: CONGRESSO BRASILEIRO DE ENGENHARIA SANITÁRIA E AMBIENTAL, 28., 2015. Anais [...]. Rio de Janeiro: ABES, 2015.
TEIXEIRA, T.C.S. Um Método Hibrido de Cobrança pelo Uso da Água Bruta: incorporando o valor econômico da água na gestão de recursos hídricos. Tese (Doutorado em Engenharia Civil) - Universidade Federal do Rio de Janeiro, Rio de Janeiro, 2012.

TEIXEIRA, T:; AZEVEDO, J.P.S. Cobrança pelo Uso da Água e Sustentabilidade de Bacias Hidrográficas: uma proposta para a bacia do Rio São Francisco. Bahia Análise \& Dados, v. 23, n. 2, p. 397-408, 2013.

TEIXEIRA, T; VEIGA, K:; AGUIAR, G.; JULIEN, D. Cobrança Pelas Perdas no Setor de Saneamento na Bacia Hidrográfica do Rio São Francisco: estudo de impacto sobre prestadores selecionados. In: CONGRESSO BRASILEIRO DE ENGENHARIA SANITÁRIA E AMBIENTAL, 30., 2019. Anais [...]. Natal: ABES, 2019 